\title{
Integration of Remote Sensing and Geographic Information System for Urban Air Quality Assessment
}

\author{
Zhonghua $\mathrm{Jin}^{1}$, Yan Yuan ${ }^{2, *}$ \\ ${ }^{1}$ Department of Urban Planning \& Environmental Policy, Texas \\ Southern University, Houston, 77004, United States; ${ }^{2}$ School of Urban \\ Design, Wuhan University, Wuhan, 430072, China
}

\begin{abstract}
As environment degradation has caught more and more public attentions, many studies have shown the severe health impacts that air pollution may cause to the general public. Various studies have made efforts using remote sensing technology to study environmental pollution. Concerns of Particle Matter concentration has become one popular subject to examine urban air quality. As the oil \& gas industry has been rapidly growing in the Mexico gulf area, the air quality is as well dramatically influenced along the Texas coastal line. In this study, we use remote sensing and Geographic Information System (GIS) technologies to examine the urban area air quality in Houston-Galveston region, where air pollution has become a major environmental pollution concern. In order to obtain accurate results, we compare MODIS satellite derived data and ground monitoring air quality data using a simplified conventional model. In addition, this study use PCI Geomatica, a software that processes Landsat 8 satellite image to test the impacts of temperature changes on $\mathrm{PM}_{2.5}$ level, mainly focus on high population dense area. Satellite derived results and site monitoring results will be integrated and use GIS to analyze the spatial distribution of social and economic impacts on population, race, and income.
\end{abstract}

Keywords:Remote Sensing, GIS, $P M_{2.5}$, Temperature, Satellite Image.

\section{Introduction}

Benefit from the development of oil and gas industry in the gulf area, city of Houston has become one of the largest cities in the US, with total population over 2 million in 2013 according to the government official report. The city as well has developed the second largest capacity of oil refineries in the US. Hundreds of chemical institutions are built alone the Houston shipping channel in the east part of town. Industrial pollution has become one of the major concerns for public health, especially of the air pollution. Moreover, the state of Texas is the largest state in the US and is heavily relying on automobile transportation. In the city of Houston, because most employment is centralized in downtown and several sub-centers, it results in heavy traffic in the inner city area 
during rush hours. Transportation emission is another major source contributes to air pollution in urban area.

Numerous studies have shown that explosion to particulate matters has certain health effects that it may cause respiratory and cardiovascular diseases (Keuken et al., 2013). $\mathrm{PM}_{2.5}$ has drawn a major concern since it has relatively smaller size, with a diameter of $2.5 \mu \mathrm{m}$ or less, and is able to flow with air into human respiratory system causing severe health impairments (Strak et al., 2012; Tai et al., 2010). Urban area activities are the main source of PM emissions, includes road traffic, energy production, industry emission, household activities, and etc. (Keuken et al., 2013). Therefore, assessment of ground $\mathrm{PM}_{2.5}$ level in urban environment is very important to the public health. Even though that PM level can be obtained from air monitoring sites, where air quality monitors can be set up, ground level monitoring is considered not efficient on reporting actual PM levels due to the fact that points measurements cannot record the spatial distribution of PM in a large urban area (Benas, Beloconi, \& Chrysoulakis, 2013).

Many studies have adapted remote sensing technology with GIS to analyze the changes in various aspects of earth surface, such as ground water, coastal line, forest, as well as air quality. This study introduces a new satellite imagery processing application, Geomatica, combine with traditional remote sensing models to present an additional method on air quality analysis. This study also applies GIS as a primary tool to analyze the social economic impacts of $\mathrm{PM}_{2.5}$ level in Houston-Galveston region, TX. The $\mathrm{PM}_{2.5}$ level is also affected by many variables, such as temperature, humidity, wind speed, and etc., all of which need to be taken consideration estimating the ground $\mathrm{PM}_{2.5}$ level (Tai et al, 2010). Geomatica is able to process satellite image to provide an overall changes of urban temperature.

The technology of assessing particulate matters using satellite data has been widely applied in many studies, where the terms of AOT (aerosol optical thickness) or AOD (aerosol optical depth) are employed as important measurements of atmosphere assessment (Retalis et al., 2010; Song et al., 2014). The volume of aerosol load in the atmosphere indicates certain PM2.5 level (Retails et al., 2010). Satellite remote sensing provides a tool to assess the AOD/AOT using MODIS (Moderate Resolution Imaging SpectorRadiometer) satellite data.

Various models have been developed to compare the $\mathrm{PM}_{2.5}$ results between ground level monitoring data and satellite derived data (Song et al., 2014). Most satellite based AOD analysis imported MODIS observed data at regional level, within one country or an entire continent. (Lee et al., 2012; \& Song et al., 2014). However, the technology is still applicable to urban air quality analysis by examining estimated the relationship between AOD that is estimated from satellite data and ground monitoring data (Kumar et al., 2007). Beside of AOD, $\mathrm{PM}$ is also affected by other meteorology variables, such as wind speed, 
humidity, temperature, and etc. (Hu et al., 2013; Keuken et al., 2013; Song et al., 2014). Due to concentrated energy consumption, traffic, and other human activities, high population dense areas have relatively higher concentration of particulate matter levels. Among all the meteorology indicators, unlike wind speed and humidity, both of which are mother nature's act, temperature is the only variable that can be affected by human activities. Studies focus on the topic of urban heat island have concluded the fact that urban center area or other high volume energy consumption spots have relatively high ground temperatures than rural area (Plocoste et al., 2014; Thomas et al., 2014; O’Malley et al., 2014). Correspondingly, not only the temperature, but also the $\mathrm{PM}_{2.5}$ level is distinguishable from the urban area to the rural area. Study on the relationship between temperature and the concentration of particulate matters focus on the urban landscape is more logical.

\section{Methodology}

USGS (U.S. Geological Survey) has launched its newest version Landsat 8 that provides satellite image of entire earth surface every 16 days (USGS, 2014). This study employs PCI Geomatica 2014 for satellite imagery processing in order to obtain the qualified dates over the year to perform PM level analysis according to an urban temperature change analysis within the study area.

Also, we use aerosol optical depth that is derived from MODIS satellite data to compare with ground level point-monitoring results. This technology has been maturely developed and many models have been discussed and reviewed in the past, such as ACE model, ANN model, generalized additive model, semiempirical model, and etc. (Song, et al., 2014). However, most of those models are predicting $\mathrm{PM}_{2.5}$ results on a global base lacking of local concentrations (Hu et al., 2013). A geographically weighted regression (GWR) model is able to improve the results based on local regression analysis to examine the overall relationships over $\mathrm{PM}_{2.5}$, AOD, and other possible indicators (Hu et al., 2013; Song et al, 2014). Here we propose to simplify a conventional statistical model developed by Song et al. in 2014 to compute $\mathrm{PM}_{2.5}$ level and its relationships with other indicators. Since the $\mathrm{PM}_{2.5}$ concentration can be affect by temperature, wind speed, humidity, and etc. (Hu et al., 2013; Song et al., 2014), $\mathrm{PM}_{2.5}$ can be expressed in a liner regression model, as following:

$$
\mathrm{PM}_{2.5}=\alpha+\beta_{1} \times \mathrm{AOD}+\beta_{2} \times \mathrm{TEMP}+\beta_{3} \times \mathrm{WS}+\beta_{4} \times \mathrm{RH}
$$

Where: $\mathrm{PM}_{2.5}$ is the dependent variable;

AOD represents aerosol optical depth;

TEMP represents the local temperature;

WS represents local wind speed;

RH represents relative humidity;

$\alpha, \beta_{1}, \beta_{2}, \beta_{3}$, and $\beta_{4}$ are fit coefficients 
In this equation, we will also test the hypothesis that when urban area temperature changes, while all the other variables stay constant, $\mathrm{PM}_{2.5}$ will be affected in population dense area. To acquire urban area temperature information, we need to integrate Geomatica and GIS. Since the $\mathrm{PM}_{2.5}$ concentration in rural area is relatively low, temperature changes cause minimum impact. Urban area temperature is relatively higher due to high concentration of energy consumption. Urban temperature distribution can be obtained from Landsat 8 satellite image processing using Geomatica. GIS will be used to define urban area according to population or employment concentration. GIS also provides us a tool to analyze the social economic impacts of air quality to the study area, including population distribution and income level. We are able to acquire useful population data from US Census Bureau, and county boundary map (Fig. 1) from HGAC (HoustonGalveston Area Council). Combine with the results of satellite imagery processing and AOD analysis, GIS will use 2010 population and income data that is acquired from American Community Survey to illustrate geographical impacts.
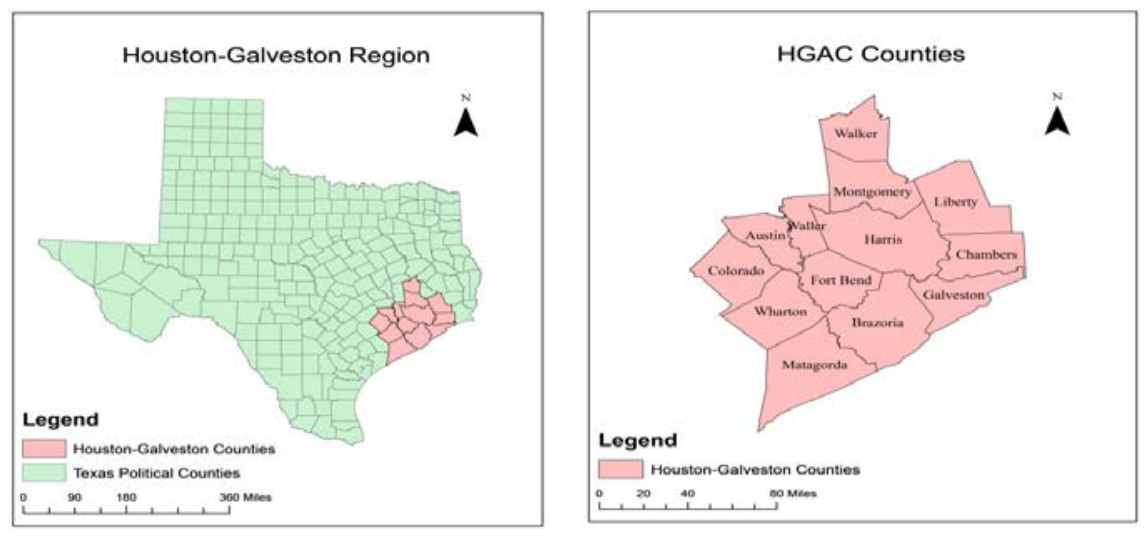

Fig. 1 Houston-Galveston Regional GIS map

Using GIS Spatial Statistics Tools, the GWR model can be utilized to analyze the relationships between PM level and its predicting variables that are AOD, WS, TEMP, RH, and etc.. GWR results can be calculated in GIS using the Geographically Weighted Regression function to visualize the PM concentration level in the study area (Song et al., 2014). Here we apply the GWR model that is tested in Song et al.'s study, as following:

$$
\mathrm{PM}_{2.5} \sim \mathrm{AOD}+\mathrm{TEMP}+\mathrm{RH}+\mathrm{WS}
$$

In equation (2), we test the correlation between $\mathrm{PM}_{2.5}$ and its indicators. Based on the results from existing studies on $\mathrm{PM}_{2.5}$ estimating using satellite remote sensing technology, it is more effective to predict rural area PM concentration than urban landscape (Song et al., 2014). However, when take the meteorological 
variable into consideration, the remote sensing results can be significantly affected, especially when the degree of temperature, relative humidity, and wind speed changes. It is proven that the GWR model provides more accurate results regarding to this issue (Hu et al., 2013; Song et al., 2014). To determine the single effect of temperature on particulate matter concentration, we focus on the urban area with high population density and areas with high volume of industrial production. We use Geomatica to identify the area with relatively high temperature and test the PM2.5 levels. In order to validate the temperature conditions that is obtained from satellite image processing, we apply ArcGIS to compute and visualize the population and employment distribution.

\section{Data}

\subsection{Ground site monitoring data}

Houston-Galveston area air monitoring data can be acquired from Texas Commission on Environmental Quality (TCEQ) database that provides air monitoring data by month. Hourly average air quality data can be retrieved at TCEQ air monitoring stations from its website. There are over 100 ground air quality monitoring devices, CAMs, in the Houston-Galveston region. There is a great amount of work collecting $\mathrm{PM}_{2.5}$ level from each CAM and convert all the data into a database, but it provide us a first-hand and accurate data set.

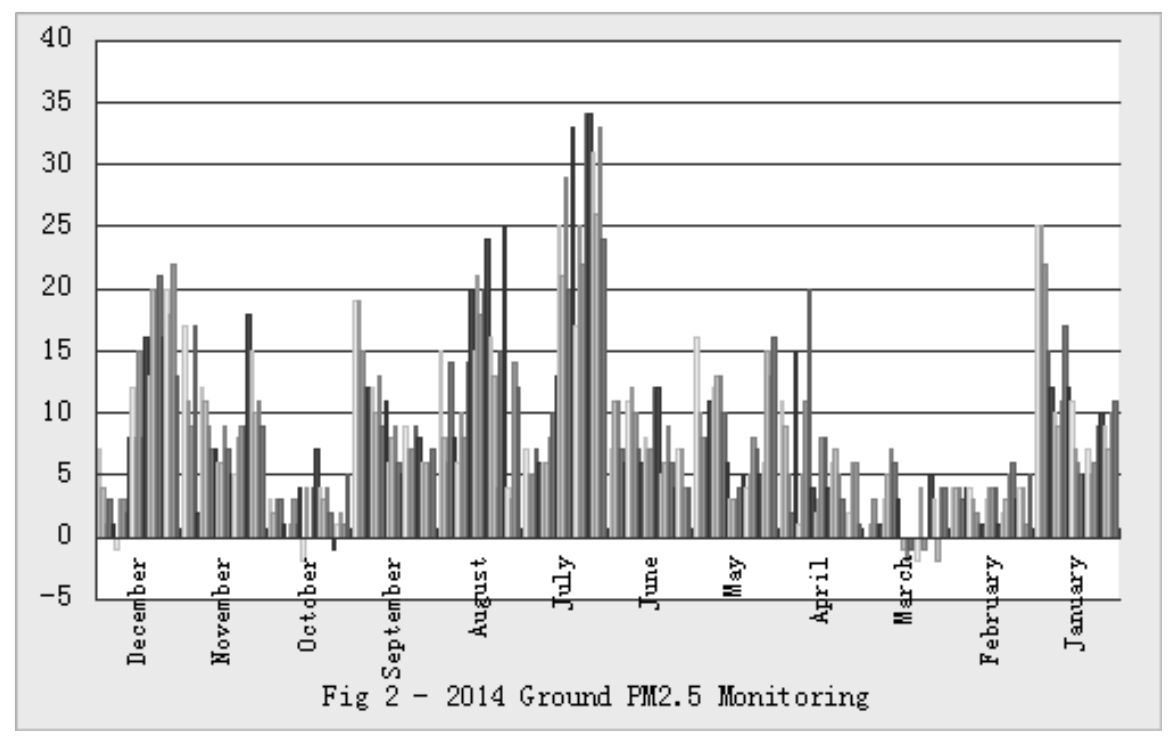

TCEQ ground monitoring $\mathrm{PM}_{2.5}$ data is report by every hour. Fig 2 is the ground monitoring results retrieved on the first day of each month in 2014. The acceptable $\mathrm{PM}_{2.5}$ local condition is measured in micro-grams per cubic meter. Fig 3 represents different $\mathrm{PM}_{2.5}$ values that are recorded at the same time of a 
day from 9 different locations of the study area in 2014. The difference indicates that heavy traffic and inner city areas may show higher $\mathrm{PM}_{2.5}$ records at the same time of a day, and those CAMs locate further into the suburbs have relatively lower records. To validate satellite remote sensing analysis, we compare the trend of ground monitoring data with the satellite derived results. However, ground monitoring results can only represent accurate $\mathrm{PM}_{2.5}$ at a very local level. This issue can be solved using remote sensing to map the particulate matter distribution over the whole urban area. GIS analysis compliments remote sensing and statistical analysis for better results.

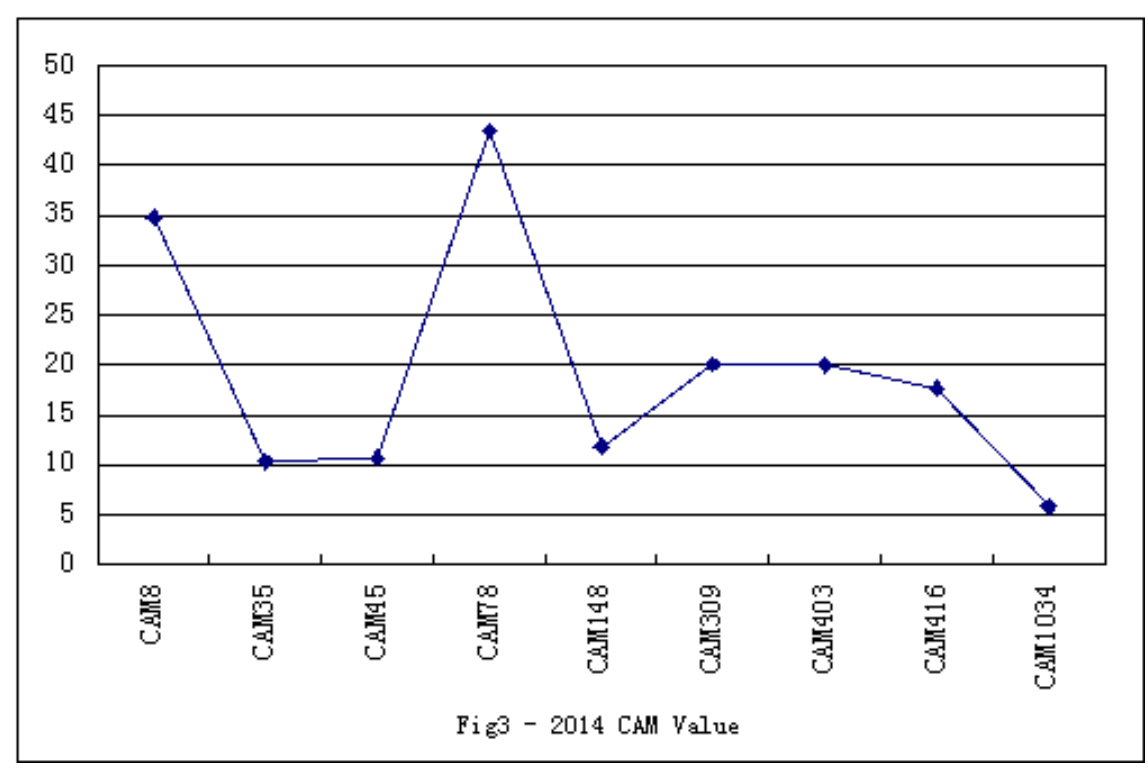

\subsection{Satellite image}

Geomatica satellite image processing is able to provide us the qualified time zone for MODIS data retrieval as well as the temperature change information over time in an urban landscape. Many studies have included temperature as a significant indicator that affects $\mathrm{PM}_{2.5}$ level in air quality analysis (Kumar et al., 2007; Benas et al., 2013; Song et al., 2014). USGS (U.S. Geographic Survey, http://www.usgs.gov) produces aerial photographs and images through its NAPP (National Aerial Photography Program) and NHAP (National High Altitude Photography). In this study, we will acquire Land Sat 8 satellite images using Geomatica to perform atmospheric correction and data visualization. Urban area temperature changes can be acquired from satellite imagery using Geomatica.

\subsection{MODIS \& GIS data}

MODIS multi8spectral data has 250- to 1000- meter moderate resolution, and is available from the Terra Satellite and Aqua Satellite (http://modis- 
atmos.gsfc.nasa.gov). These two satellites provide complementary global coverage measuring the overall solar radiance and light reflection (Retails, et al., 2010). We retrieve AOD at $550 \mathrm{~nm}$ from NASA LAADS Web level 2 aerosol data set.

GIS data includes geographic, social, and economic information of HoustonGalveston region. HGAC provides city and county boundary maps that could be utilized in our study. Population, employment, income data can be found through US Census (http://www.census.gov) and American Community Survey. We can identify the urban center by the calculation of population density or job density using GIS. The major social issue related to air pollution is the segregation by race or income. This study not only analyze the urban $\mathrm{PM}_{2.5}$ conditions, but also provide an insight of the impacts on affected social groups. Using ArcGIS, we are able to easily identify the racial and income level distributions within the study area. A conclusion can be draw to describe the health impact of air quality to certain classes.

\section{Conclusion}

Different from most previous studies using GIS and remote sensing for environmental monitoring, this study imports additional satellite imagery processing application, Geomatica, to analyze the effects of temperature on $\mathrm{PM}_{2.5}$ distribution in urban environment. This method can also be applied to test the temperature impacts on any other air pollutants. However, the spatial distribution of air pollutants is affect by various variables, such as wind speed, humidity, and etc. This study is currently on its proposal phase and requires further work on data collection and processing. More research should be done to test when the variable value changes, other than temperature, how the pollutants' distribution trends change. Also, the results from ground point monitoring and satellite observation needs thorough examination and preparation before statistical analysis. The short come of ground level monitoring is that it can only represent local air quality instead of providing actual spatial distribution in the whole area. To overcome this obstacle, integration between satellite derived results and ground monitoring results is need.

\section{Acknowledgements}

This project is funded and sponsored by the National Natural Science foundation of China project under Grant Number51208388.

\section{References}

[1] Benas, N., Belocoi, A., Chrysoulakis, N. (2013), Estimation of Urban $\mathrm{PM}_{10}$ concentration, based on MODIS and MERIS/AATSR synergistic observations, Atmospheric Environment, 79, 448-454. 
[2] Dawson, J.P., Adams, P.J., \& Pandis, S.N., (2007) Sensitivity of PM2.5 to climate in the Eastern US: a modeling case study, Atmospheric Chemistry and Physics, 7, 4295-4309.

[3] Hu, X., Waller, L.A., Al-Hamdan, M.Z., Crosson, W.L., Estes Jr., M.G., Estes, S.M., Quattochi, D.A., Sarnat, J.A., \& Liu, Y. (2013), Estimating groundlevel $\mathrm{PM}_{2.5}$ concentrations in the southeastern U.S. using geographically weighted regression, 121, 1-10.

[4] Keuken, M.P., Moerman, M., Voogt, M., Blom, M., Weijers, E.P., Rockmann, T., \& Dusek, U. (2013) Source contributions to $\mathrm{PM}_{2.5}$ and $\mathrm{PM}_{10}$ at an urban background and a street location, Atmospheric Environment, 71, 26-35.

[5] Kumar, N., Chu, A., Foster, A. (2007), An empirical relationship between $\mathrm{PM}_{2.5}$ and aerosol optical depth in Delhi Metropolitan, Atmospheric Environment, 41, 4492-4503.

[6] Lee, S., Serre, M., Donkelaar, A., Martin, R., Burnett, R., Jerrett, M. (2012), Comparison of geostatistical interpolation and remote sensing technologies for estimating long-term exposure to ambient $\mathrm{PM}_{2.5}$ concentration across the continental United States, Environmental Health Perspectives, 120, 1730-1732.

[7] Lin, C., Li, Y., Yuan, Z., Lau, A.K.H., Li, C., \& Fung, J.C.H. (2015), Using satellite remote sensing data to estimate the high-resolution distribution of ground-level $\mathrm{PM}_{2.5}$, Remote Sensing of Environment, 156, 117-128.

[8] O’Malley, C., Piroozfarb, P.A.E., Farr, E.R.P., \& Gates, J. (2014), An investigation into minimizing urban heat island (UHI) effects: a UK perspective, Energy Procedia, 62, 72-80.

[9] Plocoste, T., Jacoby-Koaly, S., Molinie, J., \& Petit, R.H. (2014), Evidence of the effect of an urban heat island on air quality near a landfill, Urban Climate, 10(4), 745-757.

[10] Retails, A., Hadjimitsis, D.G., Michaelides, S., Tymvios, F., Chrysoulakis, N., Clayton, C.R.I., \& Themistocleous, K. (2010), Comparison of aerosol optical thickness with in situ visibility data over Cyprus, Natural Hazards and Earth System Sciences, 10, 421-428.

[11] Song, W., Jia, H., Huang, J., Zhang, Y. (2014), A satellite-based geographically weighted regression model for regional $\mathrm{PM}_{2.5}$ estimation over the Pearl River Delta region in China, Remote Sensing of Environment, 154, 1-7.

[12] Strak, M., Janssen, N.A.H., Godri, K.J., \& et al. (2012) Respiratory Health Effects of Airborne Particulate Matter: The Role of particle size, composition, and Oxidative potential-the RAPTES project, Environmental Health Perspectives, 120 (8), 1183-1189.

[13] Tai, A.P.K., Mickley, L.J., \& Jacob, D.J. (2010), Correlations between fine particulate matter $\left(\mathrm{PM}_{2.5}\right)$ and meteorological variables in the United States: Implications for the sensitivity of $\mathrm{PM}_{2.5}$ to climate change, Atmospheric Environment, 44, 3976-3984.

[14] Thomas, G., Sherin, A.P., Ansar, S., \& Zachariah, E. (2014), Analysis of urban heat island in Kochi, India, using a modified local climate zone classification, Procedia Environmental Science, 21, 3-13. 